\title{
La comedia de figurón en la escena del siglo XXI: El narciso en su opinión, por Rafael Calatayud (2009) y El lindo don Diego, por Carles Alfaro (2013)
}

Purificació Mascarell

Universitat de València, España

purificacio.mascarell@uv.es

Fecha de recepción: 27/12/2018. Fecha de aceptación: 28/02/2019.

\section{Resumen}

Este artículo analiza dos espectáculos recientes de comedias clásicas de figurón. Por un lado, el montaje de 2009 de El narciso en su opinión, obra del dramaturgo Guillén de Castro, a cargo del director valenciano Rafael Calatayud para Teatres de la Generalitat Valenciana. Por otro lado, el espectáculo de El lindo don Diego, de Agustín Moreto, que dirigió en 2013 el también director valenciano Carles Alfaro, como director invitado de la CNTC. El objetivo es diseccionar los parámetros conceptuales y estéticos bajo los que se perfila escénicamente (y se recibe por el público contemporáneo) la figura del atildado, pretencioso, extravagante y afeminado "lindo" áureo.

\section{The comedia de figurón on the 21st Century Stage: El narciso en su opinión by Rafael Calatayud (2009) and El lindo don Diego by Carles Alfaro (2013)}

\begin{abstract}
This article analyzes the recent versions of two classical comedias de figurón (originated in the Spanish Golden Age). One of them is the 2009 production of Guillén de Castro's $E l$ narciso en su opinión, which was directed by Rafael Calatayud for the Teatres de la Generalitat Valenciana. The other one is Agustín Moreto's El lindo don Diego, directed by Carles Alfaro for the Compañía Nacional de Teatro Clásico in 2013. The objective is to dissect the conceptual and aesthetic parameters by which the type of the pretentious, extravagant and effeminate Golden Age "lindo" is characterized (and perceived by contemporary audiences).
\end{abstract}

Palabras clave teatro clásico siglo de oro comedia de figurón espectáculo escenografía Guillén de Castro Agustín Moreto

\section{Keywords}

Classical Theatre Spanish Golden Age Comedia de figurón Performance Scenography Guillén de Castro Agustín Moreto
La presencia en las tablas actuales del figurón, tipo de personaje muy particular de las comedias del Siglo de Oro, plantea el reto de cómo conectarlo dramatúrgicamente con el público contemporáneo. En este trabajo se presentan las claves de dos propuestas 
escénicas que han logrado esta conexión de manera exitosa en los últimos años. Se trata de dos montajes pertenecientes a compañías públicas, dirigidos por directores valencianos, Carles Alfaro y Rafael Calatayud. Aunque antes, quizá, cabe contextualizar mínimamente el análisis de estos espectáculos mediante unas pocas pinceladas teóricas.

La comedia de figurón, o con figurón, según Víctor García Ruiz - aunque no interesa aquí entrar en matices terminológicos o en cuestiones de género dramático- se ha interpretado como un subgénero de la comedia de capa y espada o de la de enredo, pues sus tramas, su ambientación y su tono entran plenamente en estas categorías ${ }^{1}$. La principal característica de la comedia de figurón, aquello que la particulariza dentro del corpus de las de enredo, se encuentra en el protagonismo de un personaje masculino que dinamita la conducta prototípica del galán de estas comedias. Porque, con sus rarezas e hipérboles paródicas, el personaje titular subvierte las estrategias dramáticas típicas de los caballeros del teatro aurisecular.

Como consecuencia de esta transgresión o desvío, el personaje resulta cómico y provoca situaciones risibles debido a su anómala conducta: su vestir bizarro y atildado con extravagantes adornos, su exagerada obsesión estética, sus afirmaciones pretenciosas y pedantes, sus movimientos presuntuosos, la práctica de una vanidad, indiscreción, jactancia y engreimiento desmedidos, le hacen arrastrar un epíteto harto empleado para referirse a estos figurones o lindos: el de ridículos. Y el efecto cómico les acompaña. Como sintetiza muy atinadamente Elena di Pinto:

\begin{abstract}
A la lumbre de la risa, en efecto, surge el figurón igual que otros personajes destinados a solazar lectores y espectadores. Es evidente que el primer y mejor motor de la risa es la ruptura de la norma, en este caso de la norma de la comedia nueva, y aún más concretamente de la comedia de capa y espada en la que el decoro, la compostura, la modestia, los valores como los de la honra, el honor, el valor [...] son la columna vertebral de una sociedad bien ordenada y el espejo en el que el espectador ha de mirarse. (2007:99)
\end{abstract}

Pero si la finalidad de la risa que provocaba el lindo en el público coetáneo a los textos tenía, junto a la vertiente burlesca y festiva, una cierta deriva moralizadora - con una advertencia: la desmesura no es buena, deben seguirse los cauces marcados para la conducta masculina aceptada socialmente, salirse de esas líneas varoniles deviene problemático y peligroso...-, ¿qué sentido tiene este personaje-tipo, incrustrado en su complejo contexto original de normas sociales, visto desde hoy? ¿Qué papel puede jugar en la escena contemporánea el figurón clásico y qué abordaje ideológico o estético puede absorber? ¿Con qué mecanismos teatrales es posible acercarlo al espectador contemporáneo desde sus particularidades áureas? A continuación, se analiza cómo se resuelven estas cuestiones en dos adaptaciones escénicas de relieve.

\section{El narciso en su opinión, por Rafael Calatayud (2009)}

En 2009, dentro de un plan trazado desde Teatres de la Generalitat Valenciana para rescatar el teatro escrito en castellano por autores valencianos del $\mathrm{XVII}^{2}$, se presenta El narciso en su opinión en el Teatre Rialto. En enero de 2010, las funciones se trasladan al Teatro Pavón de Madrid, como compañía invitada de la CNTC durante esa temporada. Es la primera vez que esta pieza de Guillem de Castro ${ }^{3}$ se representa en la época moderna y, también, la última ocasión hasta hoy.

En esta apuesta institucional por partida doble, subyace la intención de reivindicar a un dramaturgo que, frente a tótems como Lope, Calderón y, en menor medida, Tirso, ha sido sepultado por la fama de la única de sus obras que forma parte del canon escénico
1. Víctor García Ruiz explica: “El figurón es un tipo, no un género. Su presencia no engendra una fórmula genérica, "comedia de figurón”, diversa de la comedia de capa y espada. Sencillamente se integra en ella. Por tanto, es mejor hablar de comedias (o novelas) con figurón y no de comedias de figurón" (Casa, García Lorenzo y Vega García-Luengos, 2002:146).

2. Dentro de este homenaje a la Academia de los Nocturnos de Valencia, destacan los montajes de La viuda valenciana de Lope de Vega, por el director Vicente Genovés en 2008, y El mercader amante, de Gaspar de Aguilar, estrenado en 2009 bajo dirección de Jaime Pujol. Asimismo, en 2011, Antoni Tordera dirige una versión de Los locos de Valencia con Teatres de la Generalitat, entidad pública que, en la última década, ha prestado una atención especial a los clásicos españoles.

3. Cito a la estudiosa Gemma Domingo, autora de una tesis completísima sobre el dramaturgo valenciano: “"Guillem" es la forma originaria, correspondiente a su nombre valenciano, en que aparece transcrito el antropónimo de nuestro insigne dramaturgo en numerosos documentos de la época, tales como la partida de bautismo, las partidas de desposorios, diversos testamentos, así como en algunas ediciones antiguas de sus obras. Posteriormente, una desafortunada castellanización del nombre valenciano, que debería haber dado lugar a la forma "Guillermo", generalizó, entre la crítica literaria, el uso del "famoso" "Guillén» (2006: 21). En este artículo se usa, por tanto, su nombre original. 
moderno del teatro clásico. Me refiero a Las mocedades del Cid, ampliamente editada en la modernidad y cuyo éxito escénico se relaciona, por una parte, con la imitación que firmó Pierre Corneille en su Le Cid y con su temática histórico-legendaria, que gozó de privilegios escénicos durante los años del franquismo (Mascarell, 2014:61-66).

Así pues, de un total de veintisiete obras de autoría fiable atribuida a Guillem de Castro, con títulos tan sugerentes como El conde Alarcos, Progne y Filomena, La fuerza de la sangre, El perfecto caballero o Los enemigos hermanos, la presencia del dramaturgo en la escena moderna se ha limitado a la repetición, cada pocos años, de Las mocedades del Cid en escena (se destacan los cuatro montajes del Teatro Español de Madrid en 1941, 1968, 1990 y 1997), el del Teatro de Cámara de Barcelona (1956), y a un puñado de títulos desde los años 90 hasta hoy: dos montajes de Los mal casados de Valencia (CNTC, 1994; Compañía El Corral de la Olivera, 2013); La fuerza de la costumbre (Compañía José Caride, 1994); y El curioso impertinente (CNTC, 2007). Para un autor tan poco explorado en las tablas, supuso un revulsivo la puesta en escena de una de sus mejores comedias, hasta el momento desconocida por el público, y bajo el sello de calidad de Teatres de la Generalitat Valenciana, el equivalente valenciano al Teatre Nacional de Catalunya, pero con menos presupuesto y menos renombre.

El narciso en su opinión, escrita entre 1612 y 1615, aparece recogida en casi todos los manuales e historias del teatro, únicamente, como precedente de la comedia de figurón, en general, y de El lindo don Diego, de Agustín de Moreto, en particular. La pieza de Moreto, en cualquier caso, siempre es considerada superior a la de Castro, sin profundizar en los valores originales del Narciso. El argumento es enrevesado, como corresponde a toda comedia de enredo y, con el cambio pertinente de nombres y algún matiz en la trama, puede servir para sintetizar también el de El lindo don Diego: don Gutierre, el lindo, el narciso, y su primo don Gonzalo llegan a Madrid porque su tío, don Pedro, quiere casar a su hija doña Brianda con uno de los dos, el que ella elija. Lo que no saben es que ella ya ha elegido: está enamorada del marqués. Tadeo, el criado harto de las extravagancias de su amo don Gutierre, cambia de bando y decide ayudar al marqués y a doña Brianda en sus propósitos. Para ello, disfrazan a la criada Lucía de dama, la hacen pasar como hermana del marqués y consiguen que el narciso, ciego y ensimismado, se enamore de ese espejismo de nobleza. Al final, claro, don Gutierre queda solo, sin matrimonio y burlado, como buen galán suelto de comedia de capa y espada.

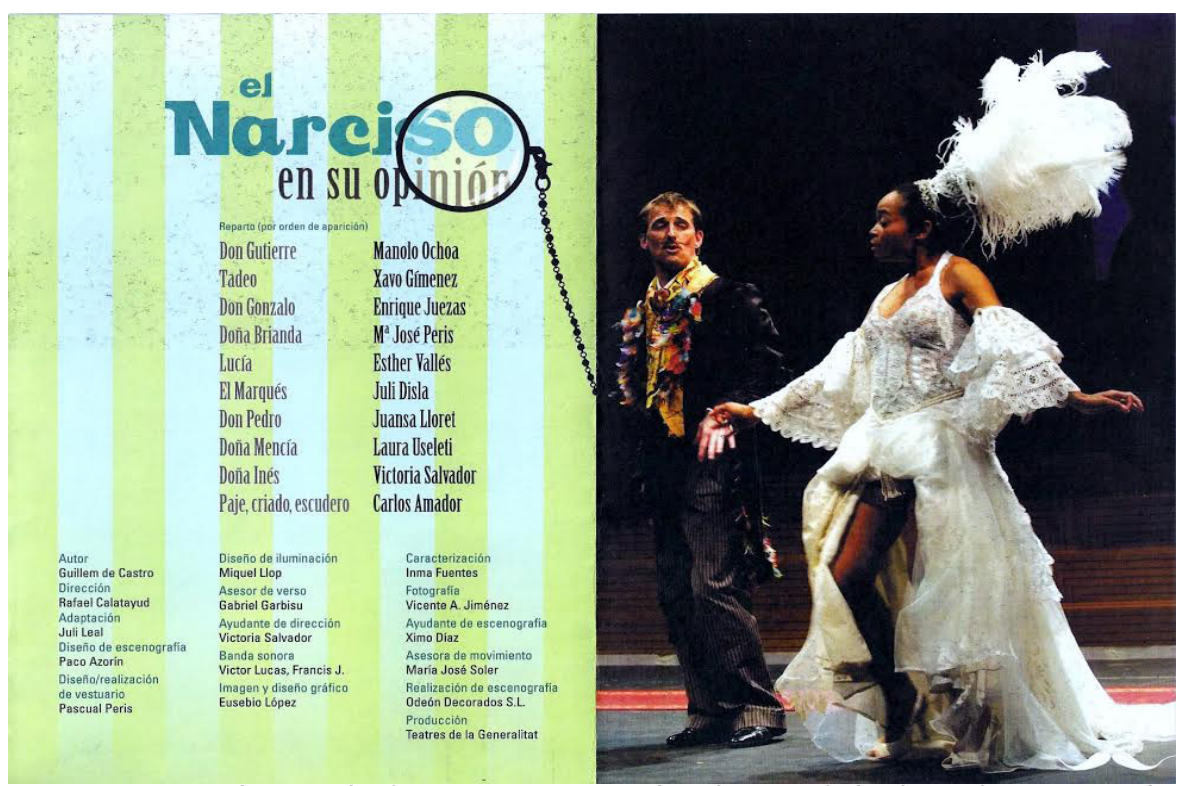

Figura 1. Programa de mano de El narciso en su opinión, dirigido por Rafael Calatayud (2009). Gentileza Teatres de la Generalitat Valenciana 
El director de escena Rafael Calatayud aborda El narciso a través de una actualización, tal como viene definido este término en el célebre Diccionario del teatro de Patrice Pavis:

Operación que consiste en adaptar al tiempo presente un texto antiguo, teniendo en cuenta las circunstancias contemporáneas, el gusto del nuevo público y las modificaciones de la fábula que impone la evolución de la sociedad. La actualización no introduce cambios en la fábula central, preserva la naturaleza de las relaciones entre los personajes. Sólo varían la fecha y el marco de la acción. (1996:34)

Así pues, Calatayud cambia el marco ambiental de la acción y la ubica en un momento indefinido entre los años 30 y los años 50 del siglo XX, y en un contexto característico de la alta sociedad: un hotel de lujo en el centro de Madrid, del que es propietario el padre de doña Brianda, don Pedro, y al que llegan, desde Valencia y como invitados, los dos primos en busca de novia.

La escenografía, diseñada por Paco Azorín, se inspira en la estética art déco y luce en madera noble, con dos puertas giratorias a cada extremo del escenario, una breve escalera central y otras dos laterales, para subir al primer piso, de manera que el espacio permite múltiples formas de entrada y salida a escena. Azorín explica:

Mi reto prioritario ha sido crear una localización para la acción a partir de la combinación casi imposible de muchos espacios diferentes [ ], intentando que todo ello pudiera ser estrafalariamente creíble y posible para los personajes que lo van a habitar durante unos instantes. Rafael Calatayud ha tenido la idea de situar la acción en un momento indefinido entre los años 30 y los años 50. Se trata de unas décadas de elegancia y desenfredo. Arquitectónicamente he querido hacer un guiño a la arquitectura déco de líneas rectas, sobria y elegante pero acercándola a los años 5o, en un ejercicio no realista de credibilidad escénica (Herreras, 2009:43).

El establecimiento hotelero también alberga unos grandes almacenes donde comprar productos de London, Madrid, Roma, Milano o New York, tal como se lee en el rótulo central. Así, el espacio enlaza con las ciudades más chic del extranjero e invita al consumismo, a adquirir productos caros e innecesarios, pero que otorgan un cierto estatus y ponen de relieve la riqueza del padre de la dama protagonista.

La actualización es uno de los pilares de esta puesta en escena de Rafael Calatayud. El otro pilar se encuentra en la utilización del género del vodevil americano como referencia dramática, tanto a nivel interpretativo como del resto de elementos escénicos. El vodevil, esa comedia ligera, frívola, de argumento basado en la intriga y el equívoco, de temática amorosa y poco trascendental, pretendía entretener y provocar la hilaridad o el asombro de los espectadores (Slide, 1994). En efecto, parece la definición de una comedia de enredo clásica.

El vodevil, con frecuencia, incluía números musicales y variedades. Por eso, los personajes de El narciso en su opinión, en esta versión de Calatayud, bailan un charlestón o cantan en directo con micrófono en mano $\square$ cantan chanson francesa doña Brianda, al principio de la obra, para quejarse de su mal de amores, y don Gutierre, al final, para despedirse tras quedar soltero (debe ser porque el francés es el idioma del amor)-, o tararean la melodía del bolero Mirando al mar, de Jorge Sepúlveda, un tema de gran éxito en 1949. 


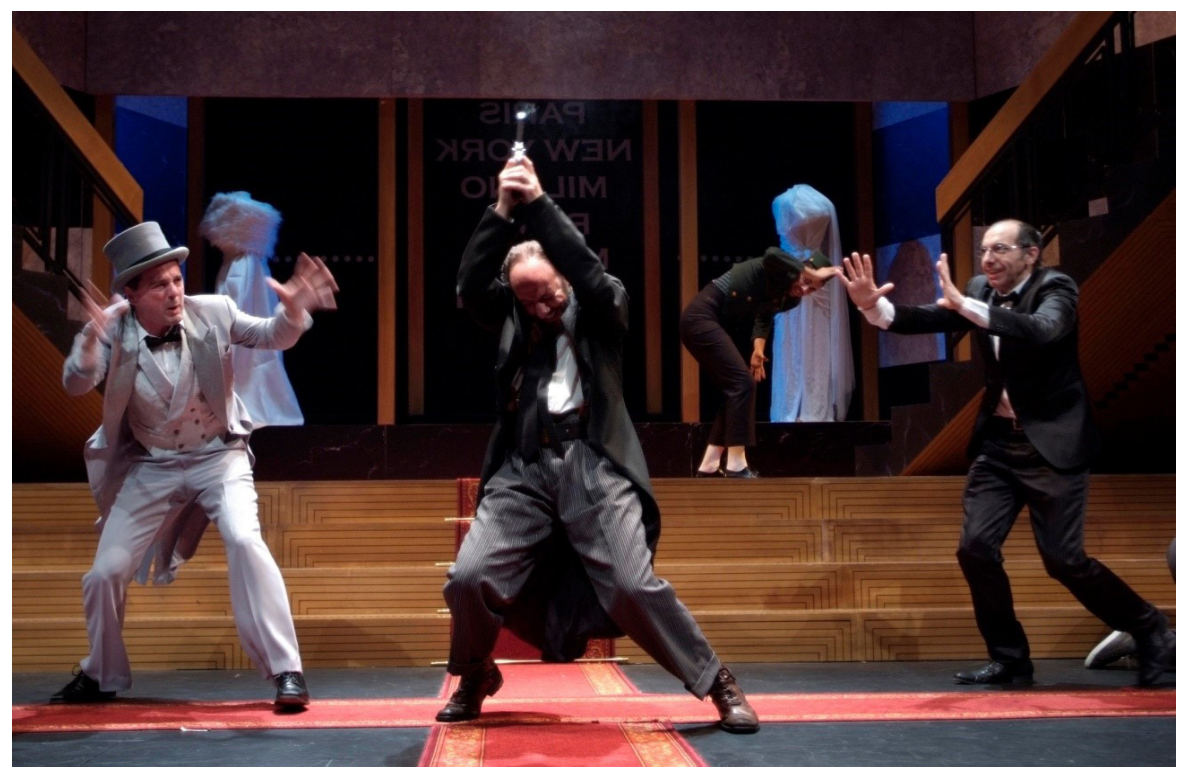

Figura 2. Escena vodevilesca con pistolas. Al centro, don Pedro, rodeado por el marqués y don Gonzalo. Gentileza Teatres de la Generalitat Valenciana

Por eso, por influencia del vodevil, la escena de seducción de la criada Lucía, travestida de alta dama, parece un número de revista musical con una vedette cargada de plumas y con las piernas desnudas prestas a emprender el típico vuelo cabaretil. Por eso, el lacayo, que es aquí un botones del hotel con su librea de botones dorados, trabaja sobre la mímica arquetípica del sirviente de vodevil. Y, por eso, en este espectáculo, hay números humorísticos que buscan provocar la risa en el público, como todas las escenas con armas. Aquí, y en virtud de la actualización, unas pistolas que nunca están en las manos que toca cuando se las necesita o que sirven para realizar pantomimas ridículas entre los diferentes galanes, remarcando así sus atisbos de cobardía.

Puede percibirse que, en esta adaptación de la comedia de Guillem de Castro, el figurón central, don Gutierre, resulta ridículo, sí, pero también que el resto de personajes, a excepción quizás de la dama doña Brianda, poseen un toque cómico que los convierte en risibles. Por tanto, los compañeros de escena del narciso no entran en contraste absoluto con su excentricidad; más bien, la acompañan y arropan, quedando ligados a ella.

Todos los personajes - menos la criada y el lacayo - van vestidos, desde el inicio de la función, como si fuesen a celebrar una boda: los caballeros y damas, van ataviados de novios, el criado Tadeo y el padre, don Pedro, de invitados. No en balde, el escaparate que preside la boutique central del hotel exhibe maniquís con vestidos de novia. Mientras doña Brianda aparece con un traje sobrio de larga cola, su prima doña Mencía, que ha de casarse con quien doña Brianda deseche, va vestida como de primera comunión, con un vestido demasiado corto y sandalias blancas con calcetines. Sus movimientos son desaforados, como de niña enrabietada, y contrastan con la edad de la actriz, una mujer madura. 


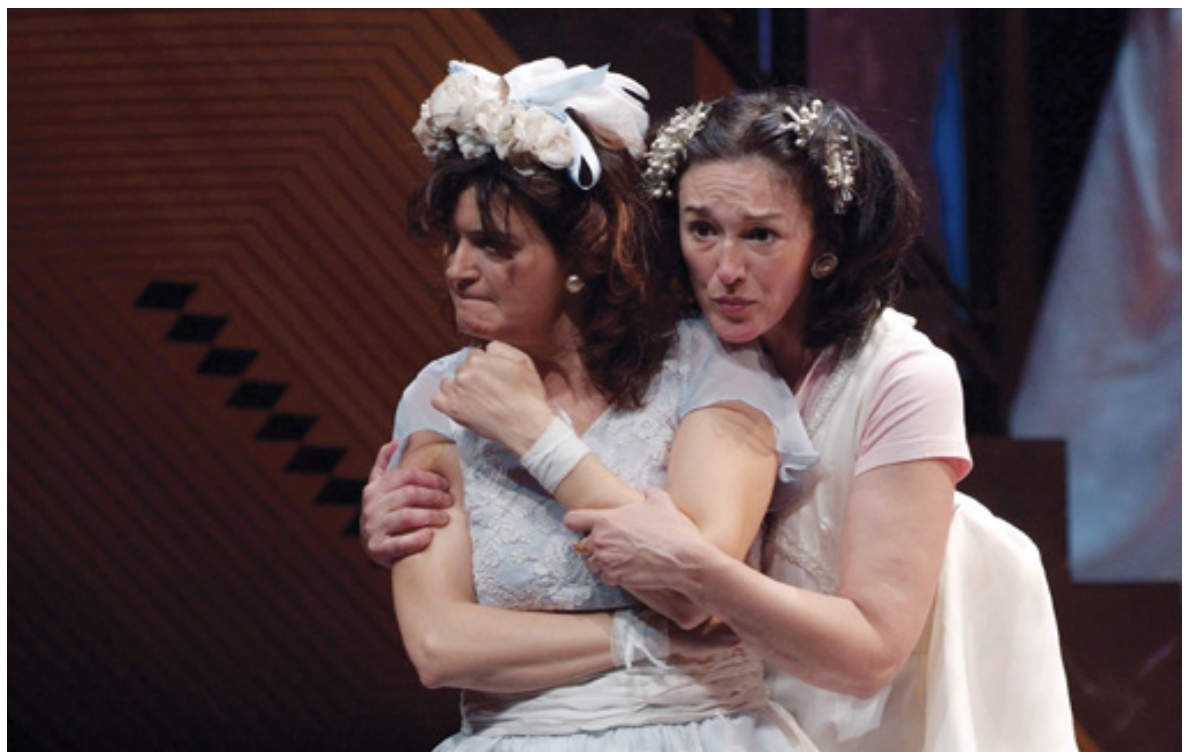

Figura 3. Las dos damas, doña Mencía en primer término y, detrás, doña Brianda. Gentileza Teatres de la Generalitat Valenciana

De hecho, tanto las damas como los galanes del elenco tienen una edad que sobrepasa la que debían tener los personajes del texto original. El efecto, obvio y buscado por parte del director, es de comicidad: todos andan desesperados en búsqueda de matrimonio cuando ya hace años que deberían estar casados. El director de la obra, Rafael Calatayud, insiste en impregnar todo el montaje bajo el concepto de fiesta nupcial:

En cuanto a la puesta en escena, el enredo se sitúa en un ambiente de celebración nupcial, incluso en el escenario aparece un escaparate de novias, creando un espacio en el que el desconcierto y el estado desubicado de los personajes se materializa en el escenario [ ]. El propósito de todos los elementos teatrales es el de actualizar la obra, haciéndola próxima y trasladándola a los años treinta o cuarenta e incluso son escenas que se podrían ver en la actualidad. [...] Al estar ambientada en una boda, los recursos son fácilmente convertibles en atemporales (Herreras, 2009:37).

Por su parte, el marqués, que habría de ser la antítesis del narciso como modelo de galán serio, se presenta en este montaje como un ser inseguro, atolondrado, que tiene miedo de entrar en la puerta giratoria cuando da vueltas rápidas o que se engancha con el lacayo con torpeza. Frente a él, don Gutierre no resulta tan patético, aunque sí un presumido que viste con chaqué de brillante solapa y sombrero de copa, siempre atento a que su tío don Pedro no le despeine y presto a embelesarse ante los espejitos que le muestra Tadeo, su criado.

Manolo Ochoa, el actor que da vida al narciso, es fruto de un buen cásting: físicamente está en las antípodas del caballero seductor, del galán valeroso, pues es de escasa estatura y muy delgado, un alfeñique rubicundo de rostro anguloso y poco agraciado. Que, no obstante, pierde ridiculez en tanto la ganan el resto de personajes que le rodean, quedando repartida la comicidad, como en todo vodevil, a lo largo y ancho del reparto.

\section{El lindo don Diego, de Carles Alfaro (2013)}

La selección del actor que encarna al figurón resulta trascendental para el éxito de la puesta en escena: son vitales sus dotes interpretativas para dar vida a un personaje que, por exceso, puede resultar cargante, y por defecto, inverosímil. 
Y aquí enlazamos con el otro montaje que propongo analizar, el de El lindo don Diego, dirigido por Carles Alfaro como director invitado de la CNTC en 2013. Su elección del televisivo actor y showman Edu Soto para el papel protagonista del lindo supuso una apuesta arriesgada. Sobre la selección de los actores, explica Alfaro:

Todo el reparto se eligió por medio de un proceso de audiciones que se llevaron a cabo en Madrid con la excepción de la de Edu Soto. Me entrevisté con él en Barcelona porque era donde estaba representando en ese momento un espectáculo propio, en clave de showman. Previamente le había visto en la versión catalana de La cena de los idiotas (Sáez Raposo, 2014: 209).

El mismo Alfaro declaraba sobre Soto que, "el hecho de ser tan popular, de estar encasillado en un tipo de papeles bastante delimitados, pudo haber jugado en su contra a la hora de ofrecerle el papel" (Sáez Raposo, 2014:209). Sin embargo, el resultado final fue sorprendente y de gran altura.

El lindo don Diego es, junto con Entre bobos anda el juego, de Rojas Zorrilla, la comedia de figurón áurea más representada en la escena moderna. Ambos títulos han sido abordados por la Compañía Nacional y han frecuentado el repertorio de las compañías privadas de clásico. Eduardo Pérez-Rasilla, en un trabajo publicado dentro del volumen de referencia El figurón: texto y puesta en escena, coordinado por Luciano García Lorenzo en 2007, ofrece un repaso de la cartelera teatral desde 1980 para observar la presencia de comedias de figurón y concluye "el balance [...] es notable en cuanto al número de las representaciones, pero restrictivo en lo que atañe a los títulos seleccionados" (2007:442). De El lindo don Diego, concretamente, se contabilizan a día de hoy hasta trece montajes diferentes ${ }^{4}$ en la base de datos de estrenos del Centro de Documentación Teatral. La versión dirigida por Carles Alfaro para la Compañía Nacional, en 2013, era esperada por los moretianos y obtuvo una muy buena acogida de crítica y público. Trabajada desde un sentido del humor ácido, plantea una base claramente esteticista desde la que se construye todo el espectáculo, como a continuación se constata.

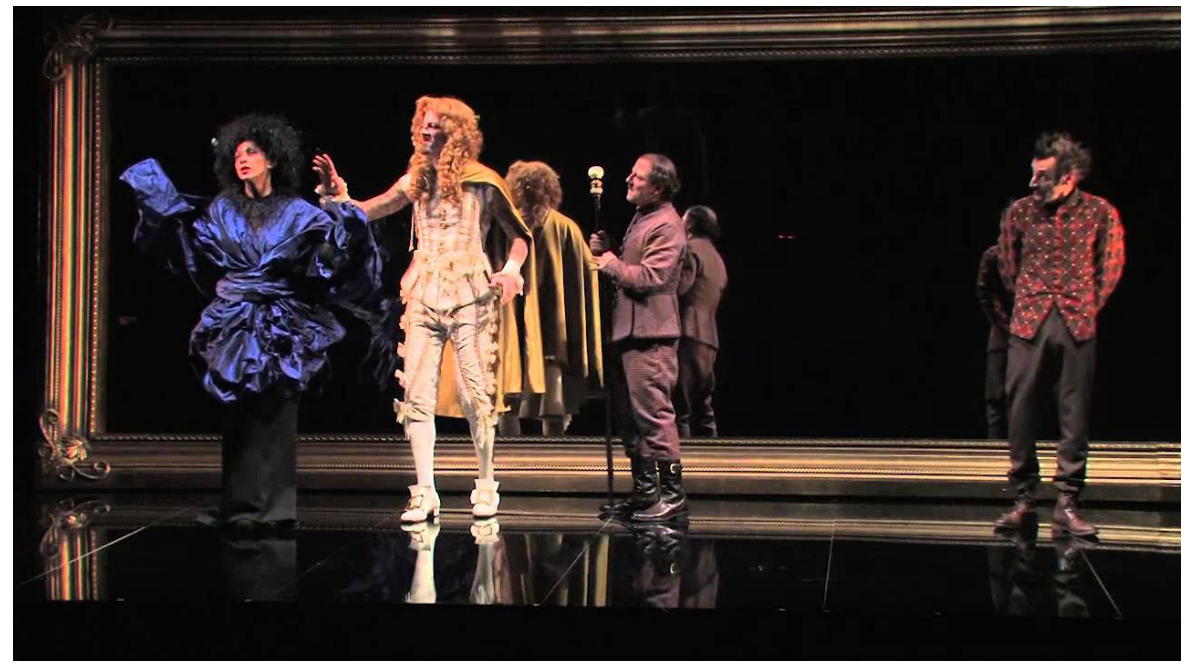

Figura 4. Imagen donde se aprecia el espejo al fondo y el suelo negro que refleja a los actores. - Gentileza: Compañía Nacional de Teatro Clásico (CNTC)

Curiosamente, el mismo escenógrafo que cuatro años antes había creado la escenografía de El narciso en su opinión, el alicantino Paco Azorín, es requerido por Alfaro para diseñar la de este Lindo don Diego. Y de una escenografía con guiños historicistas
4. Quedan aquí reflejados: Teatro Español Universitario, 1955; Compañía del Teatro Español, 1963; Pequeño Teatro de Madrid, 1980; Compañía de Teatro de Francisco Portes, 1990; Grupo de Teatro Abyla, 1992; Nuevo Teatro Estable de Burgos La Folía, 1994; Francisco Portes, 1994; Teatro Universitario de Alicante, 1997; Producciones Los Veranos de la Villa, 2001; Morboria Teatro, 2004; Darek Teatro, 2005; Compañía Nacional de Teatro Clásico, 2013. Cabe añadir la reposición del título que ha realizado Morboria en 2017. 
a las décadas de los años 30, 40 y 50 del siglo XX y su art déco, pasa ahora a una ambientación totalmente atemporal, minimalista y simbólica. El motivo del espejo, tan barroco y tan unido a la egomanía del lindo, impregna todo el espacio, desnudo de objetos bajo el criterio de la máxima sobriedad.

Al fondo, preside la escena un gran espejo, que tiene detrás un ciclorama, y durante la función hay otros dos espejos que bajan y que permiten siempre al espectador asomarse a "la acción espiándola como un voyeur. Todo ello encima de un escenario en rampa, negro brillante, donde todo se refleja nítidamente, como si de un inmenso espejo negro se tratara, acotado tan solo, en ausencia de paredes, por una cámara negra" (Zubieta, 2013:21). Con esta propuesta escenográfica, se formaliza un juego de planos y profundidades que incorpora al espectador en la escena a la vez que mantiene atrapados a los personajes en un mundo de reflejos, donde no se distingue lo real de lo irreal, la verdad de la mentira, la imagen proyectada del ser humano. Ambiente abstracto, cargado de atemporalidad y simbolismo, por tanto, para la obra de Moreto.

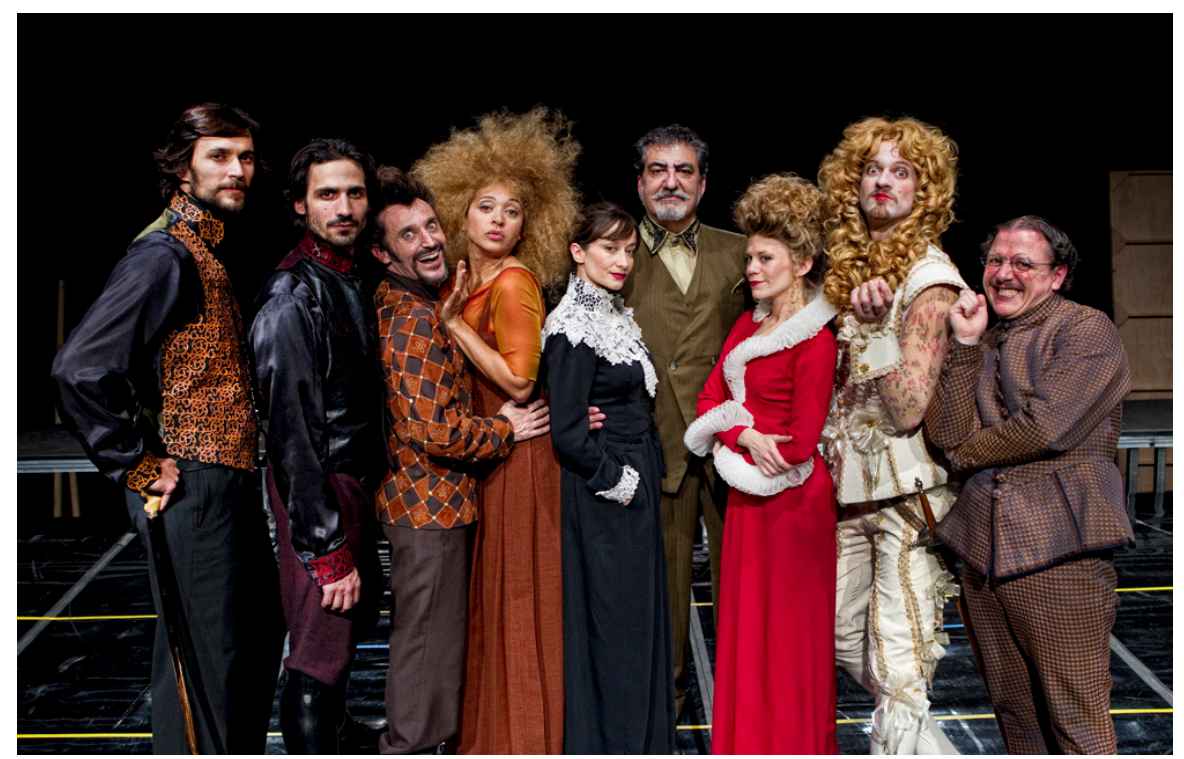

Figura 5. El elenco al completo de El lindo don Diego con el vestuario de María Araújo. - Gentileza: Compañía Nacional de Teatro Clásico (CNTC)

Esta atemporalidad, esta falta de un anclaje histórico, se consigue a través de la escenografía, como ya se ha visto, pero también a través del vestuario. Yendo más lejos, puede afirmarse que, asimismo, esta atemporalidad está trabajada desde la música firmada por Pedro Salinas: una composición sutil que ilustra las emociones íntimas de los personajes, sin ninguna referencia epocal distinguible por el público. El referente de la figurinista María Araújo para diseñar el vestuario de todos los personajes de la obra es el modisto John Galliano y su característica mezcla de elementos procedentes de diferentes épocas en un solo maniquí. Una fusión posmoderna que juega al collage de moda a partir de la superposición estética de diferentes siglos, del XVII al XXI. El espectador, ante tales figurines, experimenta desconcierto y extrañamiento pero, al mismo tiempo, es capaz de reconocer un aroma contemporáneo.

El personaje de Mosquito, por ejemplo, con un peinado estirado en puntas, maquillaje oscuro, barba de chivo y chaqueta atrevida, recuerda claramente al protagonista de un anuncio de perfumes - Solo Loewe- prodigado por revistas de moda y pantallas. En el vestuario femenino, por su parte, es posible hallar referencias actuales a Jean Paul Gaultier o Dolce\&Gabanna, con el uso de la estructura del miriñaque como volumen añadido al cuerpo - un guiño obvio a los armazones que ahuecaban los vestidos de 
las damas en la época de Moreto-. También se viaja hasta 1909 con la pieza mítica de Marià Fortuny, su vestido Delphos, inspirado en las túnicas de la antigua Grecia (Osma, 2012), un diseño que luce doña Inés durante la mayor parte de la función y con el mismo color violeta del original.

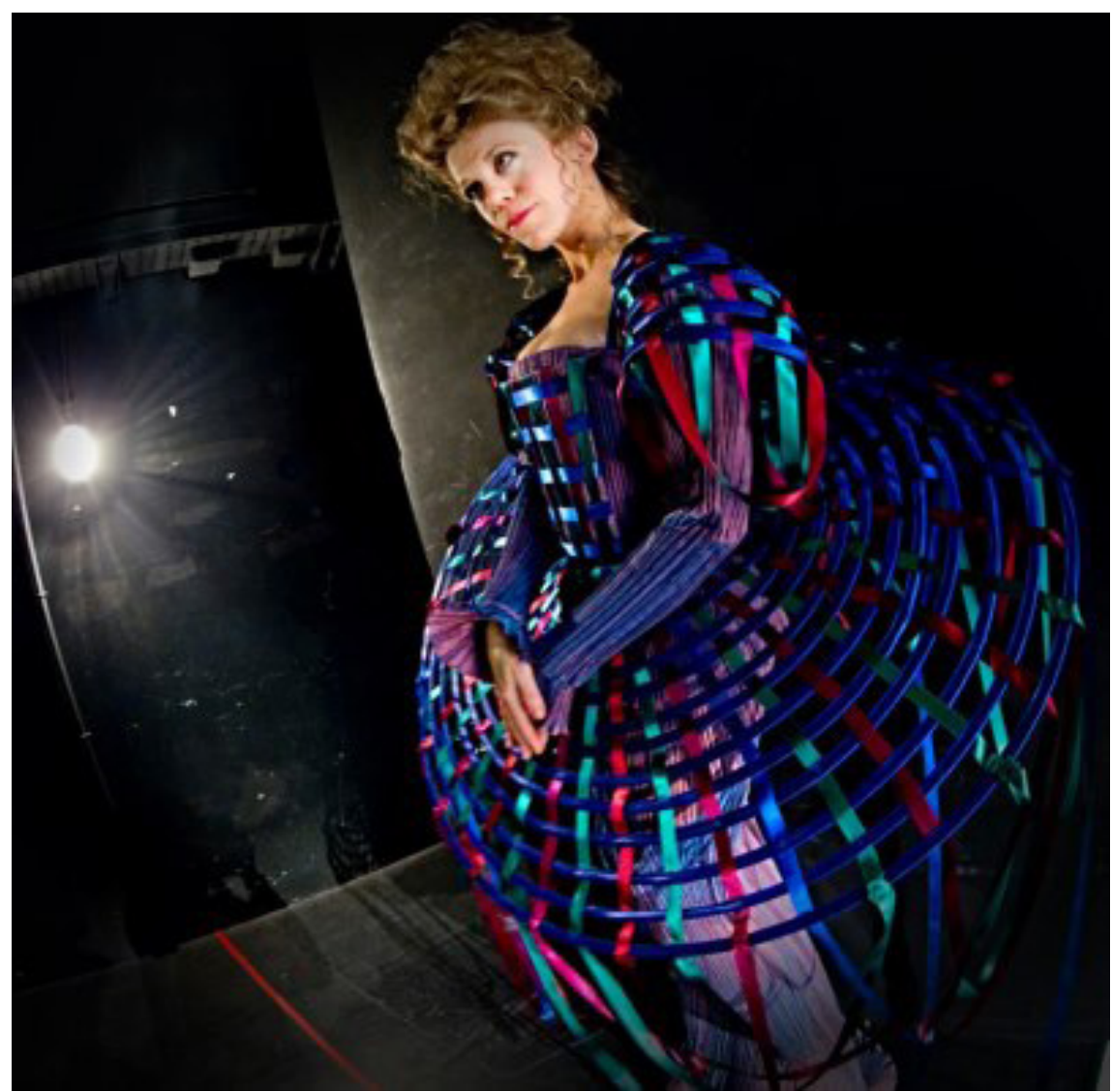

Figura 6. Doña Inés con el miriñaque superpuesto al vestido inspirado en el Delphos de Fortuny. Gentileza: Compañía Nacional de Teatro Clásico (CNTC)

Con tal miscelánea de referencias en el vestuario de los personajes, se ha prescindido del historicismo y se ha conseguido una estética antirrealista fuertemente atractiva en su rareza. Un estilo general que se aviene de manera idónea con la extravagancia del protagonista don Diego, que se distingue del resto por su look de inspiración versallesca, con guiños a Luis XVI desde la peluca a rizos hasta la capa dorada.

Edu Soto, con su especial físico y rostro, maquillado como una muñeca de porcelana, y vestido al modo rococó, saca a don Diego de la órbita del resto de personajes y confirma que su aspecto externo es fiel reflejo de su interior desquiciado: tanto su cuerpo como su mente están en un universo paralelo al de los demás. Por eso resulta tan ridículo - mucho más que el protagonista de El Narciso en su opinión de Guillem de Castro, y también más detestable y aborrecible-. Y por eso se queda solo al final de la obra, ante un espejo que le devuelve su imagen deformada, mientras se arranca la peluca de la cabeza.

Lejos de la caricatura o de la desmesura absurda - "una caricatura no habría sobrevivido más allá de los primeros cinco minutos de función sin reiterarse", Alfaro dixit (Sáez Raposo, 2014:210) -, Edu Soto imprime al personaje una credibilidad fascinante. Todos hemos conocido a esa clase de personas que se creen el ombligo del mundo y ni siquiera tratan de disimularlo. La abstracción y atemporalidad de esta puesta en escena ayudan a entender la historia del fracaso de un ególatra vanidoso como parte de la historia de la humanidad. 


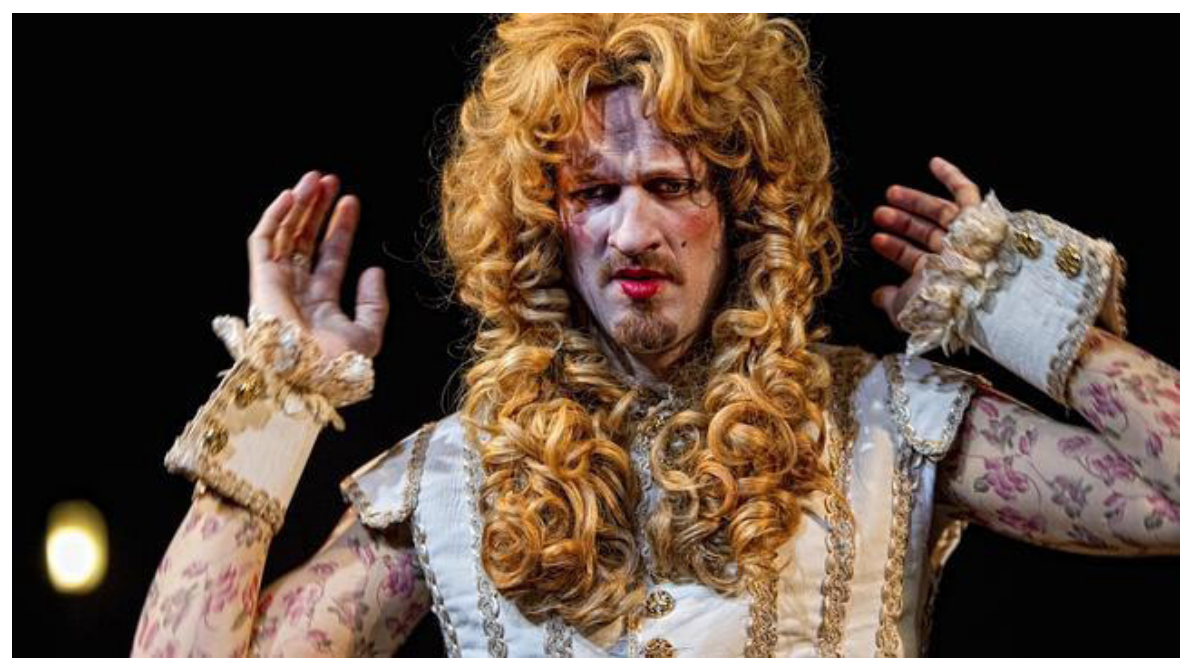

Figura 7. Edu Soto caracterizado de don Diego. - Gentileza: Compañía Nacional de Teatro Clásico (CNTC)

¿No están hoy las redes sociales plagadas de narcisos en su opinión, de lindos don diegos? Gente que se mira continuamente su reflejo en la pantalla, ese espejo actual que devuelve el ego multiplicado, magnificado, a cada like de un desconocido. Falta de autenticidad, artificio, aislamiento... Las mismas taras de los figurones clásicos, la misma realidad paralela de don Gutierre o don Diego. Tal vez, esta podría ser la base para un nuevo abordaje escénico de alguna comedia de figurón.

Hasta aquí hemos intentado exponer dos maneras contemporáneas de ocuparse en escena de este género, o subgénero dentro de la comedia de capa y espada. Dos brillantes y ágiles trabajos teatrales con dos textos clásicos para hablarnos, a los espectadores contemporáneos, de la verdad y la mentira, de la realidad y la fantasía, de la libertad y la norma, y nuestras relaciones con los demás y de nosotros mismos.

\section{Ficha técnica de El narciso en su opinión}

Actores:

Adaptación:

Dirección escénica:

Diseño de escenografía:

Diseño y realización de vestuario:

Diseño de iluminación:

Asesor de verso:

Ayudante de dirección:

Banda sonora:

Imagen:

Caracterización:

Fotografía:

Realización escenografía:
Don Gutierre, Manolo Ochoa; Tadeo, Xavo

Giménez; Don Gonzalo, Enrique Juezas; Doña

Brianda, Mํㅡ José Peris; Lucía, Esther Vallés; El marqués, Juli Disla; Don Pedro, Juansa Lloret;

Doña Mencía, Laura Useleti; Doña Inés, Victoria

Salvador; Paje, criado, escudero, Carlos Amador.

Juli Leal.

Rafael Calatayud.

Paco Azorín.

Pascual Peris.

Miquel Llop.

Gabriel Garbisu.

Victoria Salvador.

Víctor Lucas y Francis.

Eusebio López.

Inma Fuentes.

Vicente A. Jiménez

Odeón Decorados. 


\title{
Ficha técnica de El lindo don Diego
}

\author{
Actores: Don Tello, Javivi Gil Valle; Don Juan, Raúl Prieto; \\ Doña Inés, Rebeca Valls; Doña Leonor, Natalia \\ Hernández; Mosquito, Carlos Chamarro; Beatriz, \\ Vicenta Ndongo; Don Diego, Edu Soto; Don \\ Mendo, Cristóbal Suárez; Criado, Óscar de la \\ Fuente. Versión: Joaquín Hinojosa. \\ Dirección: Carles Alfaro. \\ Realización de escenografía: May Servicios, Sfumato, Mambo decorados. \\ Realización de vestuario: Goretti Puente González. \\ Ayudante de vestuario: Maite Onetti. \\ Ayudante de escenografía: Juan Sebastián Domingo. \\ Ayudante de dirección: Fefa Noia. \\ Movimiento escénico: Fuensanta Morales. \\ Asesor de verso: Vicente Fuentes. \\ Composición y dirección musical: Pablo Salinas. \\ lluminación: Pedro Yagüe. Vestuario: María Araujo. \\ Escenografía: Paco Azorín.
}




\section{Bibliografía}

"Casa, F. P., García Lorenzo, L. y Vega García-Luengos, G. (2002). Diccionario de la comedia del Siglo de Oro. Madrid: Castalia.

"Domingo Carvajal, G. (2006). Tipología de los personajes en la dramaturgia de Guillén de Castro y Bellvís (1569-1631). Barcelona: Universitat de Barcelona.

»Herreras, E. (2009). El Narciso en su opinión. Cuadernos escénicos de Teatres de la Generalitat. València: Teatres de la Generalitat.

» Mascarell, P. (2014). El Siglo de Oro español en la escena pública contemporánea: la Compañía Nacional de Teatro Clásico (1986-2011). València: Universitat de València.

» Osma, G. de (2012). Mariano Fortuny, arte, ciencia y diseño. Madrid: Ollero y Ramos Editores.

» Pavis, P. (1996). Diccionario del teatro. Barcelona: Paidós.

"Pérez-Rasilla, E. (2007). "Las escenificaciones de la comedia de figurón en el teatro español a partir de 1980". En García Lorenzo, L. (ed.), El figurón: texto y puesta en escena. (pp. 421-442). Madrid: Fundamentos.

»Pinto, E. di (2007). "Galería de retratos: figura, figurilla y figurón". En Vega García-Luengos, G. y González Cañal, R. (coord.), Locos, figurones y quijotes en el teatro de los Siglos de Oro: actas selectas del XII Congreso de la Asociación Internacional de Teatro Español y Novohispano de los Siglos de Oro: Almagro, 15, 16 y 17 de julio de 2005. (pp. 99-110). Ciudad Real: Universidad de Castilla-La Mancha.

» Sáez Raposo, F. (2014). "El verso tiene que volar, no cotidianizarse: es la estilización del discurso" (Entrevista con Carles Alfaro). En Bastianes, M, Fernández, E. y Mascarell P. (eds.), Diálogos en las tablas. Últimas tendencias de la puesta en escena del teatro clásico español. (pp. 205-218). Kassel: Reichenberger.

"Slide, A. (1994). The encyclopedia of vaudeville. Connecticut: Greenwood Press.

»Zubieta, M. (2013). El lindo don Diego. Cuadernos Pedagógicos, 43. Madrid: Compañía Nacional de Teatro Clásico. 